Clinical Research Paper

\title{
LncRNAs act as prognostic and diagnostic biomarkers in renal cell carcinoma: a systematic review and meta-analysis
}

\author{
Jianwen Chen ${ }^{1, *}$, Yalei Chen ${ }^{2, *}$, Liangyou Gu${ }^{1}$, Xintao Li ${ }^{1}$, Yu Gao $^{1}$, Xiangjun Lyu ${ }^{1}$, \\ Luyao Chen ${ }^{1}$, Guoxiong Luo ${ }^{1}$, Lei Wang ${ }^{1}$, Yongpeng Xie ${ }^{1}$, Junyao Duan ${ }^{1}$, Cheng \\ Peng $^{1}$ and Xin $\mathrm{Ma}^{1}$ \\ ${ }^{1}$ Department of Urology/State Key Laboratory of Kidney Diseases, Chinese People's Liberation Army General Hospital, \\ Beijing, China \\ ${ }^{2}$ Department of Cardiology, Beijing Anzhen Hospital affiliated to Capital Medical University, Beijing, China \\ * These authors have contributed equally to this work \\ Correspondence to: Xin Ma, email: urologist@foxmail.com \\ Keywords: IncRNA; renal cell carcinoma; clinicopathology; diagnosis; prognosis \\ Received: April 03, $2016 \quad$ Accepted: July 19, $2016 \quad$ Published: August 05, 2016
}

\section{ABSTRACT}

We conducted a systematic review and meta-analysis to investigate the clinical values, including clinicopathology, prognosis, and diagnosis of different long noncoding RNAs (IncRNAs) in renal cell carcinoma (RCC). A total of 14 eligible studies, including 10 on clinicopathological features, 11 on prognosis, and 3 on diagnosis were identified. Results revealed that metastasis-associated lung adenocarcinoma transcript 1(MALAT1) expression was associated with tumor stage (odds ratio [OR], 3.46; 95\% confidence interval [CI], 1.63-7.36; $p=0.001$ ). The high expression of MALAT1 could be considered a biomarker of the early detection of lymph node metastasis and predictor of poor survival in RCC patients, who likely manifested short overall survival (OS; hazard ratio [HR], 2.97; 95\% CI, 1.68-5.28; p<0.001). For diagnostic value, the pooled result showed that IncRNA maintained a sensitivity of 0.89 and specificity of 0.91 in RCC diagnosis, The area under the curve of 0.94 ( $95 \%$ CI, 0.92-0.96) for IncRNA in RCC diagnosis also indicated a significant advantage over other biomarkers. Our systematic review and meta-analysis demonstrated that IncRNAs could be considered biomarkers to detect lymph node metastasis and distant metastasis in early stages. LncRNAs could function as potential prognostic markers in RCC. LncRNAs could also display high accuracy for RCC diagnosis.

\section{INTRODUCTION}

It is estimated that about 66,800 Chinese will suffer from kidney cancer in 2015, and about 23,400 Chinese will die from this cancer [1]. The incidence of renal cell carcinoma has rapidly increased [2]. RCC is the most common form of kidney cancer in adults, and clear cell RCC (ccRCC) is the most common subtype; patients with advanced RCC have a 5 year survival rate of $<30 \%$ [3]. Surgery is the gold standard for localized RCC; however, this strategy provides limited benefits for patients with locally advanced or metastatic RCC; Metastatic RCC is also resistant to chemotherapy and radiotherapy; as such, new therapeutic targets should be developed. In RCC research, several genetic biomarkers, including mRNAs, such as HIF1 $\alpha$ [4], Von Hippel-Lindau gene(VHL) [4], NOTCH1 [5], S100A6 [6], and E2F1 [7], and microRNAs (miRs), such as miR-21 [8], miR-221 [9] and miR-30a [10], have been used. Long non-coding RNAs (lncRNAs) have also been extensively investigated because of their clinical usefulness and biological properties in diagnosis, prognosis, and treatment.

LncRNAs are a class of RNA with transcripts longer than 200 nucleotides and lack functional open reading frames [11].These RNAs actively function in various cell biological processes, such as cellular differentiation, proliferation, DNA damage response, and chromosomal imprinting [12]. An increasing number of studies have 
shown that lncRNAs were closely related to many human diseases, including cancer [13, 14]. Their expression profiling in various cancer types have been widely examined, and many of these lncRNAs were correlated with cancer diagnosis and prognosis. For example, IncRNA-XIST, a product of the X-inactive specific transcript gene, and lncRNA HIF 1 alpha-antisense RNA 1 (HIF1a-AS1) are up-regulated in non-small cell lung cancer (NSCLC), and can be used as a diagnostic biomarker for NSCLC screening [15]. Urothelial carcinoma-associated-1(UCA1) is highly expressed in the plasma of Gastric Cancer (GC) patients, and can be a promising noninvasive diagnostic biomarker for GC [16]. lncRNA UCA1 is also identified as sensitive diagnostic markers for bladder cancer [17]. IncRNA-ATB, a TGF$\beta$-activated lncRNA, is significantly up-regulated in hepatocellular carcinoma metastases and associated with poor prognosis [18]. HOX transcript antisense intergenic RNA (HOTAIR) is also correlated with the tumor stage and poor prognosis of non-small-cell lung cancer; the down-regulation of HOTAIR inhibits the invasion and metastasis of non-small-cell lung cancer cells through the down-regulation of HOXA5 [19]. Recent studies have shown that lncRNAs are also potential diagnostic and prognostic biomarkers of RCC; these finding suggest that these RNAs can be developed as biomarkers to guide therapeutic decisions [20-22].

However, single study may be inaccurate and insufficient because of limitations related to sample size and research programs. As such, studies should be systematically analyzed to determine the potential clinical values of IncRNAs in RCC. Thus far, meta-analysis has yet to be performed, although some reviews have been conducted regarding the evaluation of the clinical values of different lncRNAs in RCC. Likewise, the clinical values of lncRNAs have been rarely analyzed. Therefore, we systematically reviewed studies that have identified the relationship between lncRNA expression and clinical outcomes in RCC. We also included these studies in our meta-analysis if extracted data could be merged. We mainly discussed our findings in terms of the following aspects: clinicopathological features, diagnosis, and prognosis.

\section{RESULTS}

\section{Study characteristics}

A total of 464 records were retrieved from PubMed, Embase and Web of science. A total of 173 duplicate reports were excluded. After the titles were reviewed, 181 records were excluded. After the abstracts were screened, 73 records were excluded. Subsequently, the 37 remaining full-text articles were assessed, and 23 studies, including 10 without clinical data, 1 with less than 30 sample numbers, 2 with description on genetic variation, 2 duplicate articles, 2 with discussion on other diseases, 2 with discussion on IncRNA-methylation, and 4 microarray articles, were further excluded on the basis of the exclusion criteria. A total of 14 studies, including 10 on clinicopathological features, 11 on prognosis, and 3 on diagnosis, were eligible for the final analysis. All of the selected studies were nonrandomized. A flow diagram of the study selection process is shown in Figure 1.

\section{Clinicopathological features}

A total of 9 lncRNAs were described in the 10 included studies on clinicopathological features. renal cell carcinoma related transcript-1(RCCRT1) [23], protein sprouty homolog 4 intronic transcript-1 (SPRY4-IT1) [24], H19 [21], metastasis-associated lung adenocarcinoma transcript 1(MALAT1) [20, 25], and lncRNA activated by TGF- $\beta$ (ATB) [22] were up-regulated, and Cell adhesion molecule 1 anti-sense transcript-1 (CADM1-AS1) [26], neuroblastoma associated transcript-1 (NBAT-1) [27], lncZNF180-2 [28], and NONHSAT123350 [29] were downregulated. None of these studies reported that lncRNAs were significantly associated with gender and age of patients. Ellinger [28] revealed that clinicopathological characteristics were not significantly related to the expression levels of lnc-ZNF180-2. Two studies claimed that up-regulated RCCRT1 [23] and MALAT1 [25] were significantly related to tumor size. Five studies demonstrated that lncRNAs were significantly correlated with histological-grade RCC, while the most of the studies reported that lncRNAs were significantly correlated with tumor stage (Table 1). MALAT1 was detected in two studies. We constructed two-by-two tables to calculate the odds ratio (OR) and $p$ value of these two studies by extracting the raw patient number. We then combined these two studies with a total of 6 groups (Figure 2). Moderate heterogeneity was observed in one group (distant metastasis, $\mathrm{I}^{2}=54.2 \%$ ); therefore, a random effects model was used in this study; for other cases, a fixed effects model was utilized. After combining these two studies, we found that the statistical significance of one group changed. Before combination was performed, Hirata et al. [20] reported that up-regulated MALAT1 was not significantly correlated with lymph node metastasis because OR was $10.67(0.54,209.80)$. However, the pooled $\mathrm{OR}$ and $p$ values indicated that this correlation was indeed significant. The other comparisons of MALAT1 did not indicate significant changes.

\section{Prognosis}

The 11 included studies were retrospective and published over the recent two years. Quantitative real-time 


\begin{tabular}{|c|c|c|c|c|c|c|c|c|c|c|c|c|}
\hline Studies & LncRNAs & population & $\begin{array}{l}\text { Case } \\
\text { number }\end{array}$ & $\begin{array}{l}\text { Cut-off } \\
\text { value }\end{array}$ & Gender & Age & $\begin{array}{l}\text { Tumor } \\
\text { size }(\mathrm{cm})\end{array}$ & \begin{tabular}{|l} 
Histological \\
grade(I-IV)
\end{tabular} & $\begin{array}{l}\text { Tumor } \\
\text { stage(pT1-pT4) }\end{array}$ & \begin{tabular}{|l|} 
Lymph \\
node \\
metastasis
\end{tabular} & $\begin{array}{l}\text { Distant } \\
\text { metastasis }\end{array}$ & Expression \\
\hline Song 2014 & RCCRT1[23] & Chinese & 40 & fold-change & 0.085 & 0.728 & 0.046 & 0.017 & 0.022 & 0.008 & 0.003 & up-regulation \\
\hline Zhang 2014 & SPRY4-IT1[24] & Chinese & 98 & mean & 0.888 & 0.648 & 0.878 & 0.002 & $<0.001$ & 0.001 & 0.003 & up-regulation \\
\hline Yao 2014 & CADM1-AS1[26] & Chinese & 64 & median & 0.611 & 0.606 & 0.578 & 0.133 & 0.039 & NA & NA & down-regulation \\
\hline Xue 2015 & NBAT-1[27] & Chinese & 98 & median & 0.685 & 0.068 & 0.835 & 0.006 & $<0.001$ & 0.021 & NA & down-regulation \\
\hline Wang 2015 & $\mathrm{H} 19[21]$ & Chinese & 92 & fold-change & 0.993 & 0.463 & 0.087 & $<0.001$ & 0.002 & 0.001 & 0.01 & up-regulation \\
\hline Ellinger 2015 & lnc-ZNF180-2[28] & German & 91 & median & $>0.7$ & $>0.7$ & $>0.7$ & $>0.7$ & $>0.7$ & $>0.7$ & $>0.7$ & down-regulation \\
\hline Zhang 2015 & MALAT1[25] & Chinese & 106 & mean & 0.744 & 0.495 & $<0.001$ & 0.235 & 0.006 & 0.014 & 0.534 & up-regulation \\
\hline Hirata 2015 & MALAT1[20] & Japanese & 50 & median & 0.967 & 0.609 & NA & 0.217 & 0.001 & 0.003 & 0.077 & up-regulation \\
\hline Liu 2016 & NONHSAT123350[29] & Chinese & 90 & risk quotient & NA & $0.4^{*}$ & $0.21^{*}$ & NA & $0.3^{*}$ & NA & $-0.92 *$ & down-regulation \\
\hline Xiong 2016 & lncRNA-ATB[22] & Chinese & 74 & median & 0.450 & 0.363 & NA & 0.011 & 0.030 & 0.013 & 0.015 & up-regulation \\
\hline \multicolumn{13}{|c|}{$\begin{array}{l}\mathrm{NA}=\text { not available; }{ }^{*} \text { Correlation coefficient value, RCCRT1=renal cell carcinoma related transcript-1, SPRY4-IT1= } \\
\text { protein sprouty homolog } 4 \text { intronic transcript-1, CADM1-AS1=Cell adhesion molecule } 1 \text { anti-sense transcript-1, NBAT- } \\
1=\text { neuroblastoma associated transcript- } 1 \text {, MALAT1= metastasis-associated lung adenocarcinoma transcript } 1 \text {, lncRNA- } \\
\text { ATB=a novel lncRNA activated by TGF- } \beta\end{array}$} \\
\hline
\end{tabular}

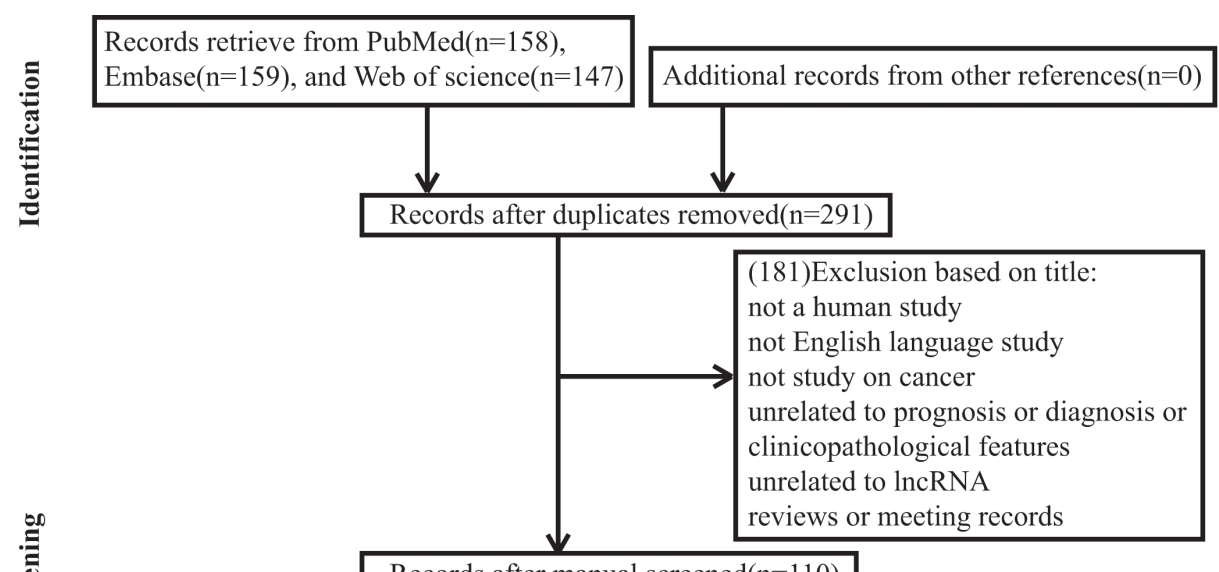

Records after manual screened(n=110)
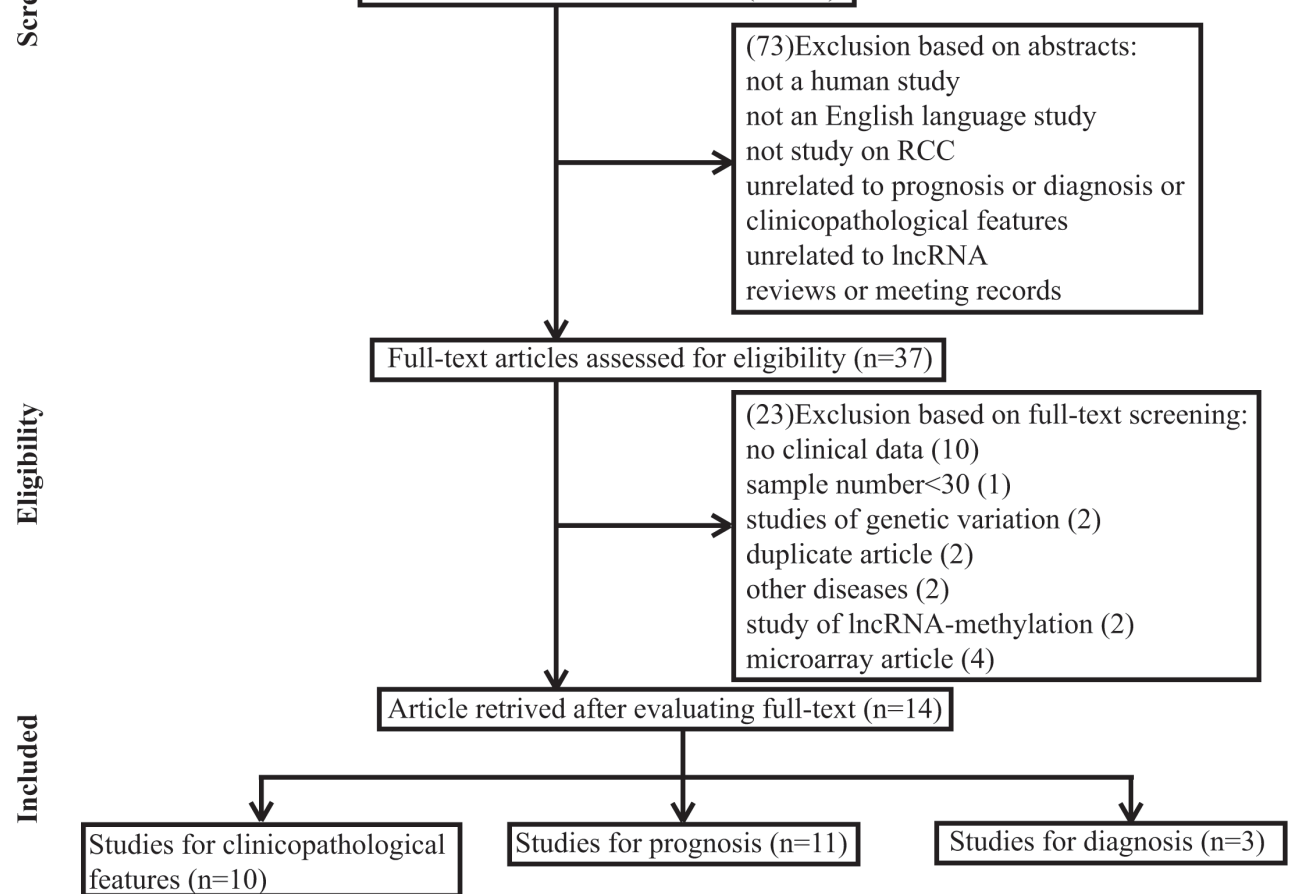

Figure 1: Flow diagram of study selection process. 
Table 2: Summary of IncRNAs used as prognostic biomarkers of RCC

\begin{tabular}{|c|c|c|c|c|c|c|c|c|c|c|c|c|c|}
\hline \multirow{2}{*}{ Study } & \multirow{2}{*}{ LncRNA name } & \multirow{2}{*}{ Region } & \multirow{2}{*}{$\begin{array}{l}\text { Study } \\
\text { design }\end{array}$} & \multirow{2}{*}{$\begin{array}{l}\text { Tumor } \\
\text { type }\end{array}$} & \multirow{2}{*}{$\begin{array}{l}\text { Tumor } \\
\text { stage }\end{array}$} & \multirow{2}{*}{$\begin{array}{l}\text { Detected } \\
\text { sample }\end{array}$} & \multirow{2}{*}{$\begin{array}{l}\text { Assay } \\
\text { methods }\end{array}$} & \multirow{2}{*}{$\begin{array}{l}\text { Cut-off } \\
\text { method }\end{array}$} & \multicolumn{2}{|c|}{ Case number } & \multirow{2}{*}{$\begin{array}{l}\text { Survival } \\
\text { analysis }\end{array}$} & \multirow{2}{*}{$\begin{array}{l}\text { HR } \\
\text { availability }\end{array}$} & \multirow{2}{*}{$\begin{array}{l}\text { Follow-up } \\
\text { month }\end{array}$} \\
\hline & & & & & & & & & $\begin{array}{l}\text { High } \\
\text { level }\end{array}$ & $\begin{array}{l}\text { Low } \\
\text { level }\end{array}$ & & & \\
\hline Song 2014 & RCCRT1[23] & China & $\mathrm{R}$ & $\mathrm{ccRCC}$ & pT1-pT4 & FT & qRT-PCR & fold change & 24 & 16 & PFS & Indirectly & $14(8-22)$ \\
\hline Zhang 2014 & SPRY4-IT1[24] & China & $\mathrm{R}$ & $\mathrm{ccRCC}$ & pT1-pT4 & FT & qRT-PCR & mean & 52 & 46 & OS & Directly & $35(0-60)$ \\
\hline Yao 2014 & CADM1-AS1[26] & China & $\mathrm{R}$ & $\mathrm{ccRCC}$ & pT1-pT4 & FT & qRT-PCR & median & 32 & 32 & OS & Directly & $\sim 80$ \\
\hline Xue 2015 & NBAT-1[27] & China & $\mathrm{R}$ & $\mathrm{ccRCC}$ & pT1-pT4 & FT & qRT-PCR & median & 49 & 49 & os & Directly & $35(0-60)$ \\
\hline Wang 2015 & H19[21] & China & $\mathrm{R}$ & $\mathrm{ccRCC}$ & pT1-pT4 & FT & qRT-PCR & fold-change & 42 & 50 & os & Directly & $\sim 60$ \\
\hline Ellinger 2015 & lnc-ZNF180-2[28] & Germany & $\mathrm{R}$ & $\mathrm{ccRCC}$ & pT1-pT4 & FT & qRT-PCR & median & 46 & 45 & PFS, CSS, OS & Directly & 144 \\
\hline Zhang 2015 & MALAT1[25] & China & $\mathrm{R}$ & $\mathrm{ccRCC}$ & I-IV & FT & qRT-PCR & mean & 46 & 60 & OS & Indirectly & $\sim 60$ \\
\hline Hirata 2015 & MALAT1[20] & Japan & $\mathrm{R}$ & $\mathrm{ccRCC}$ & pT1-pT4 & FT & qRT-PCR & median & 25 & 25 & OS & Indirectly & 47 \\
\hline Sakurai 2015 & DRAIC[30] & America & $\mathrm{R}$ & $\mathrm{ccRCC}$ & NA & FT & qRT-PCR & Z-score & 75 & 258 & DFS & Indirectly & NA \\
\hline Liu 2016 & NONHSAT123350[29] & China & $\mathrm{R}$ & $\mathrm{ccRCC}$ & pT1-pT4 & FT & qRT-PCR & RQV & 32 & 58 & DFS, OS & Indirectly & $32(3-60)$ \\
\hline Xu 2016 & EPB41L4A-AS2[31] & NA & $\mathrm{R}$ & $\mathrm{RCC}$ & I-IV & FT & qRT-PCR & median & 224 & 224 & OS & Indirectly & $\sim 108$ \\
\hline
\end{tabular}

LncRNA=long non-coding RNA; $\mathrm{R}=$ Retrospective; $\mathrm{ccRCC}=$ clear cell renal cell carcinoma; $\mathrm{RCC}=$ renal cell carcinoma; $\mathrm{FT}=$ frozen tissue; $\mathrm{qRT}-\mathrm{PCR}=$ quantities reverse transcription

polymerase chain reaction; $\mathrm{RQV}=$ risk quotient value; $\mathrm{PFS}=$ prognostic free survival; $\mathrm{OS}=$ =verall survival; $\mathrm{CSS}=$ cancer specific survival; DFS=disease free survival; $\mathrm{HR}=$ hazard ratio;

$\mathrm{NA}=$ not available, $\mathrm{DRAIC}=$ downregulated $\mathrm{RNA}$ in androgen independent cells

polymerase chain reaction (qRT-PCR) was performed to evaluate the lncRNA expression in 1,510 tissue samples. Ten different lncRNAs were associated with the prognosis of patients with RCC. The tumor type of patient in ten studies was ccRCC. The characteristics of these 11 eligible studies are presented in Table 2. The increased expressions of RCCRT1 [23], SPRY4-IT1 [24], H19 [21], and MALAT1 [20,25] were associated with poor prognosis; likewise, the decreased expressions of CADM1-AS1 [26], NBAT-1 [27], Inc-ZNF180-2 [28], NONHSAT123350 [29], down-regulated RNA in androgen independent cells (DRAIC) [30], and EPB41L4A-AS2 [31] (Figure 3) were related to poor prognosis. The sample size of these studies was more than 40; of these studies, the study of Xu et al. [31] included the largest case number of 448. H19 [21] yielded the highest hazard ratio (HR) of 3.89; by contrast, CADM1-AS1 [26] exhibited the lowest HR of 0.21. A lncRNA was considered to be a weak prognostic factor with HR between 0.67 and 1.5 [32]. At this point of view, although the correlations among all of these lncRNAs with prognosis were statistically significant, lnc-ZNF180-2 [28] and NONHSAT123350 [29] were insufficiently strong. All of these ten lncRNAs except MALAT1 were investigated in single research; MALAT1 was performed in two studies. We then conducted a meta-analysis on the relationship of MALAT1 expression and the overall survival (OS) of patients with RCC; we found that heterogeneity was not significant $\left(\mathrm{I}^{2}=0.0 \%, p=0.591\right)$. Therefore, the fixed effects model was applied. The model revealed that high MALAT1 expression could predict short OS (HR, 2.93; 95\% confidence interval [CI] 1.89-4.54; $p<0.001$; Figure 4). No conclusive graph could be generated because of the small size of this study. Therefore, we did not evaluate publication bias.

\section{Diagnosis}

In the diagnosis category, the main characteristics and Quality Assessment of Diagnostic Accuracy Studies-2 (QUADAS-2) [33] scores of each study are presented in Table 3. Three studies [28, 34, 35] containing $17 \operatorname{lncRNAs}$ provided complete diagnostic data. Of these lncRNAs, 9 were down-regulated and 8 were up-regulated. LncRNA expression was detected through qRT-PCR in these studies. A total of 171 patients with ccRCC and 129 controls comprised patients with other diseases and healthy individuals. Two of the included studies used kidney tissues as specimens and one study was based on serum. All of these studies were published in 2015 and 2016. All included studies satisfied at least four of the seven items in QUADAS-2; this indicated that the overall quality of the included studies was generally good. Figure 4 presents the forest plots of sensitivity and specificity for the 17 lncRNAs. Significant heterogeneity between these studies was observed in sensitivity and specificity data $\left(\mathrm{I}^{2}=64.00 \%\right.$ and $\mathrm{I}^{2}=89.28 \%$, respectively $)$. Therefore, the random effects model was used in this meta-analysis to calculate the pooled diagnostic parameters of the included studies. The pooled estimates of lncRNAs for the diagnosis of RCC were as follows: sensitivity(SEN), 0.89(95\% CI, 0.85-0.92); specificity(SPE), $0.91(95 \%$ CI, 0.82-0.95); positive likelihood ratio(PLR), 9.4 (95\% CI, 4.8-18.4); negative likelihood ratio(NLR), 0.12 (95\% CI, 0.09-0.18); and overall diagnostic odds ratio (DOR), 75 (95\% CI, 29-193). Figure 5 displays the corresponding summary receiver operator characteristic (SROC) curve with an area under the curve (AUC) of 0.94 (95\% CI, $0.92-0.96)$. Thus the diagnostic accuracy of lncRNAs is relatively high. We also conducted meta-regression and subgroup analysis (Figure 6) on the bias of ethnicity, 


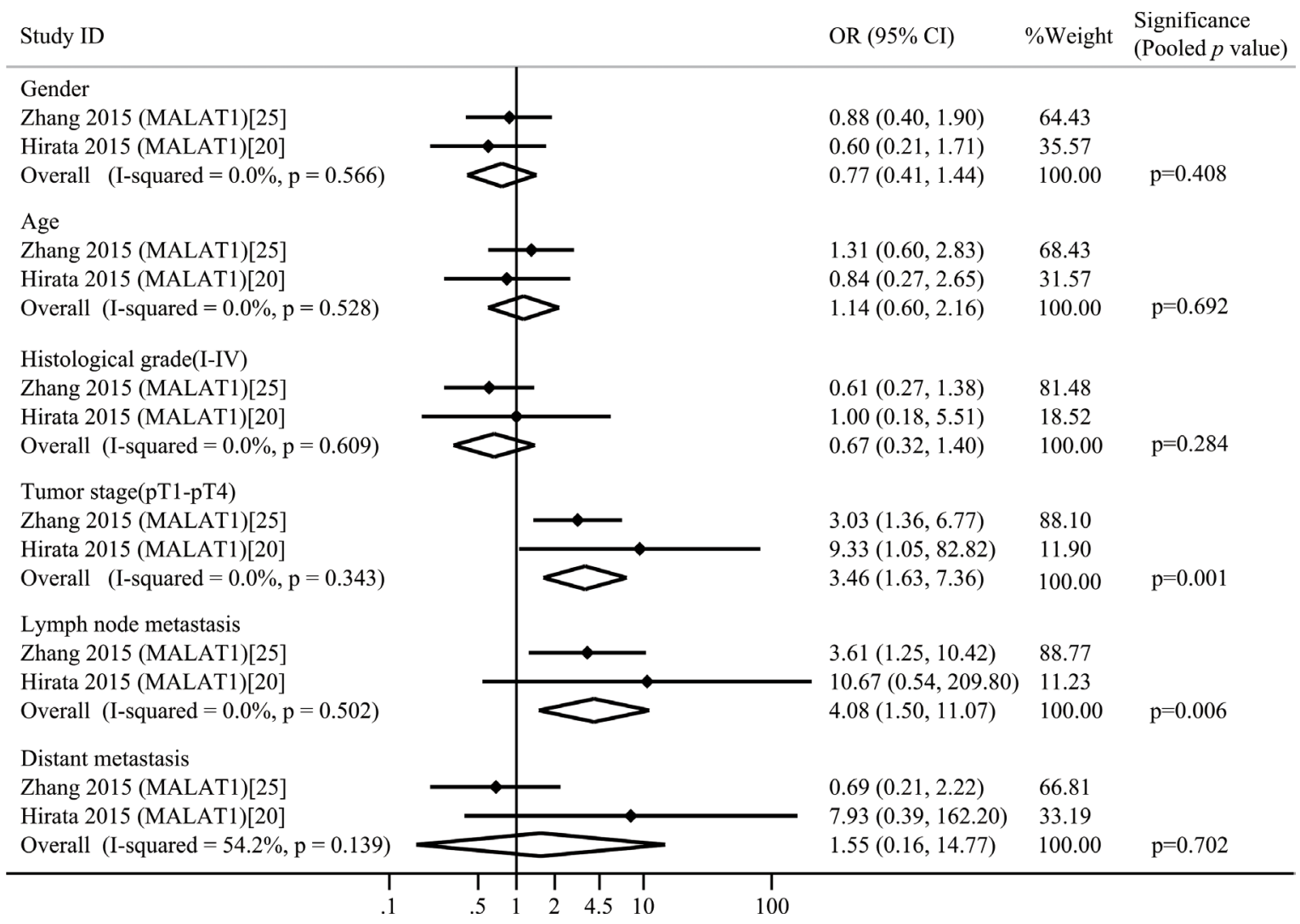

Figure 2: Forest plots of studies evaluating odds ratios (ORs) of up-regulated MALAT1 expression and the clinicopathology of RCC patients.

Study ID

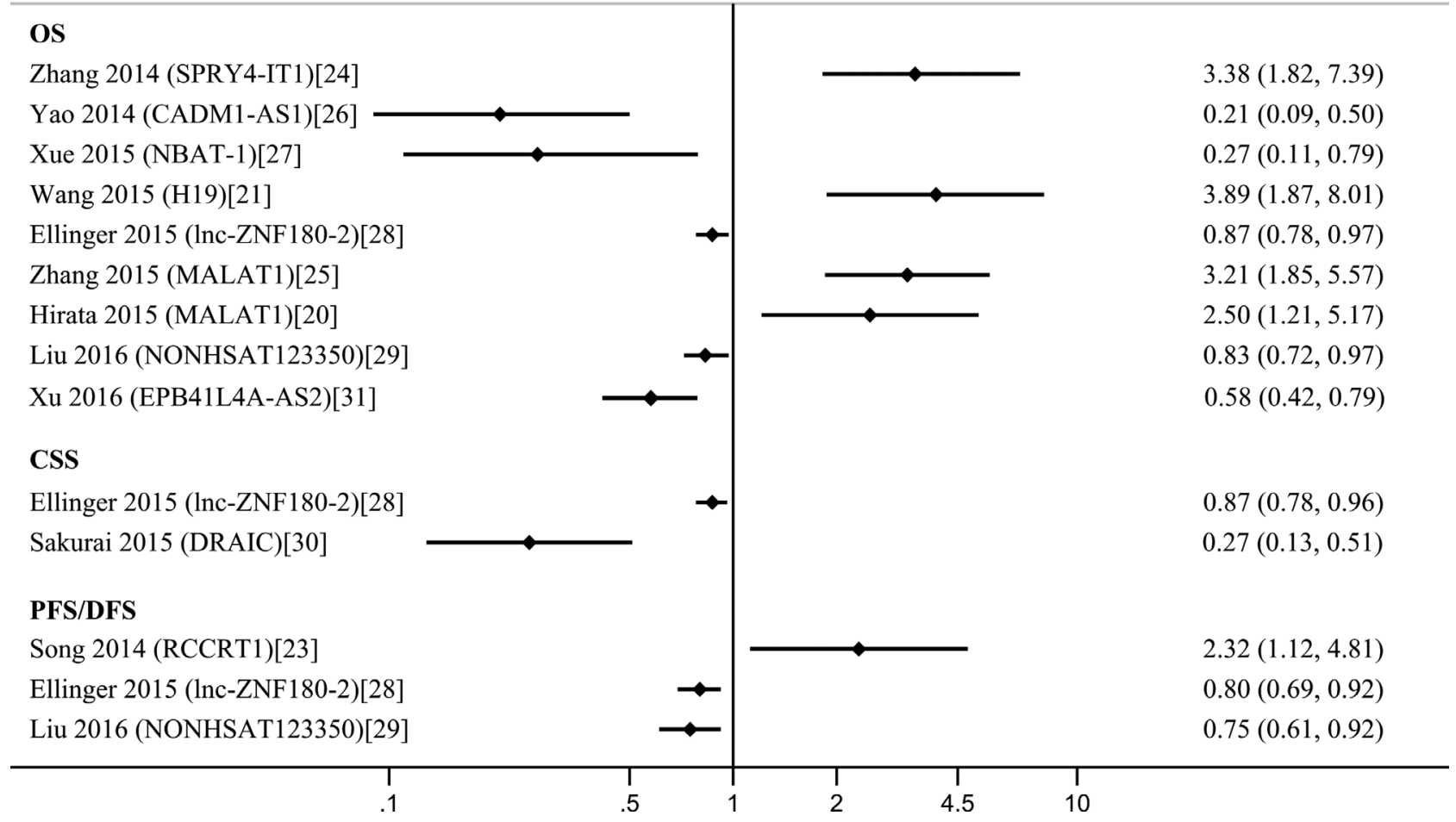

Figure 3: A display of Hazard ratios (HRs) of IncRNAs in RCC patients. The point estimate is bounded by a $95 \%$ confidence interval (CI), and the perpendicular line represents no increased risk for the outcome. OS = overall survival; $\mathrm{CSS}=$ cancer specific survival; $\mathrm{PFS}=$ prognostic free survival; DFS = disease free survival. 


\begin{tabular}{|c|c|c|c|c|c|c|c|c|c|c|c|c|c|c|}
\hline \multirow{3}{*}{\begin{tabular}{|l} 
First author \\
Ellinger[28]
\end{tabular}} & \multirow{3}{*}{\begin{tabular}{|l|}
$\begin{array}{l}\text { Publish } \\
\text { year }\end{array}$ \\
2015 \\
\end{tabular}} & \multirow{3}{*}{$\begin{array}{l}\text { Country } \\
\text { Germany }\end{array}$} & \multirow{3}{*}{\begin{tabular}{|l|} 
Ethnicity \\
Caucasian
\end{tabular}} & \multirow{3}{*}{$\begin{array}{l}\text { LncRNAs } \\
\text { lnc-CYP4A22-2/3 }\end{array}$} & \multirow{3}{*}{\begin{tabular}{|l} 
Expression \\
down-regulation
\end{tabular}} & \multirow{3}{*}{\begin{tabular}{|l|} 
SE(\%) \\
90.0
\end{tabular}} & \multirow{3}{*}{$\begin{array}{l}\text { SP(\%) } \\
55.9\end{array}$} & \multirow{3}{*}{\begin{tabular}{|l} 
AUC \\
0.790
\end{tabular}} & \multirow{2}{*}{\multicolumn{2}{|c|}{\begin{tabular}{|l|} 
Sample size \\
$\begin{array}{l}\text { Cases } \\
\text { Controls }\end{array}$ \\
\end{tabular}}} & \multirow{2}{*}{\multicolumn{2}{|c|}{\begin{tabular}{|l}
$\begin{array}{l}\text { Mean } \\
\text { age(yr) }\end{array}$ \\
$\begin{array}{l}\text { Cases } \\
\text { Controls }\end{array}$
\end{tabular}}} & \multirow{3}{*}{\begin{tabular}{|l}
$\begin{array}{l}\text { Detected } \\
\text { sample }\end{array}$ \\
Frozen tissue
\end{tabular}} & \multirow{3}{*}{\begin{tabular}{|l} 
QUADAS \\
4
\end{tabular}} \\
\hline & & & & & & & & & & & & & & \\
\hline & & & & & & & & & 102 & 50 & 66 & 64.9 & & \\
\hline Blondeau[34] & 2015 & Germany & Caucasian & lnc-FZD1-2 & up-regulation & 85.5 & 94.2 & 0.931 & 55 & 52 & 62.9 & 62.1 & Frozen tissue & 5 \\
\hline Blondeau[34] & 2015 & Germany & Caucasian & lnc-SLC30A4-1 & up-regulation & 90.9 & 96.2 & 0.942 & 55 & 52 & 62.9 & 62.1 & Frozen tissue & 5 \\
\hline Blondeau[34] & 2015 & Germany & Caucasian & lnc-BMP2-2 & up-regulation & 85.5 & 100.0 & 0.912 & 55 & 52 & 62.9 & 62.1 & Frozen tissue & 5 \\
\hline Blondeau[34] & 2015 & Germany & Caucasian & lnc-SPAM1-6 & up-regulation & 83.6 & 94.2 & 0.900 & 55 & 52 & 62.9 & 62.1 & Frozen tissue & 5 \\
\hline Blondeau[34] & 2015 & Germany & Caucasian & lnc-ITPR2-3 & up-regulation & 90.9 & 96.2 & 0.941 & 55 & 52 & 62.9 & 62.1 & Frozen tissue & 5 \\
\hline Blondeau[34] & 2015 & Germany & Caucasian & lnc-CPN2-1 & up-regulation & 90.9 & 98.1 & 0.942 & 55 & 52 & 62.9 & 62.1 & Frozen tissue & 5 \\
\hline Blondeau[34] & 2015 & Germany & Caucasian & lnc-ТTC34-3 & down-regulation & 98.1 & 96.4 & 0.990 & 55 & 52 & 62.9 & 62.1 & Frozen tissue & 5 \\
\hline Blondeau[34] & 2015 & Germany & Caucasian & lnc-ACACA-1 & down-regulation & 94.2 & 100.0 & 0.966 & 55 & 52 & 62.9 & 62.1 & Frozen tissue & 5 \\
\hline Blondeau[34] & 2015 & Germany & Caucasian & lnc-LCP2-2 & down-regulation & 98.1 & 89.1 & 0.955 & 55 & 52 & 62.9 & 62.1 & Frozen tissue & 5 \\
\hline Blondeau[34] & 2015 & Germany & Caucasian & lnc-FOXG1-2 & down-regulation & 96.2 & 89.1 & 0.954 & 55 & 52 & 62.9 & 62.1 & Frozen tissue & 5 \\
\hline Blondeau[34] & 2015 & Germany & Caucasian & lnc-RP3-368B9.1.1-1 & down-regulation & 86.5 & 94.5 & 0.938 & 55 & 52 & 62.9 & 62.1 & Frozen tissue & 5 \\
\hline $\mathrm{Wu}[35]$ & 2016 & China & Asian & LncLET & down-regulation & 70.8 & 59.3 & 0.741 & 24 & 27 & NA & NA & serum & 6 \\
\hline $\mathrm{Wu}[35]$ & 2016 & China & Asian & PVT1 & up-regulation & 70.8 & 63.0 & 0.733 & 24 & 27 & NA & NA & serum & 6 \\
\hline $\mathrm{Wu}[35]$ & 2016 & China & Asian & PANDAR & down-regulation & 75.0 & 63.0 & 0.738 & 24 & 27 & NA & NA & serum & 6 \\
\hline $\mathrm{Wu}[35]$ & 2016 & China & Asian & PTENP1 & down-regulation & 79.2 & 77.8 & 0.840 & 24 & 27 & NA & NA & serum & 6 \\
\hline $\mathrm{Wu}[35]$ & 2016 & China & Asian & Linc00963 & up-regulation & 83.3 & 66.7 & 0.812 & 24 & 27 & NA & NA & serum & 6 \\
\hline
\end{tabular}

LncRNA=long non-coding $\mathrm{RNA} ; \mathrm{RCC}=$ renal cell carcinoma; $\mathrm{SE}=$ sensitivity; $\mathrm{SP}=$ specificity; $\mathrm{AUC}=$ area $\mathrm{under}$ the curve; NA=not available; QUADAS=quality assessment of diagnostic accuracy studies

lncRNA expression level, and detected sample types. We found that detection process and ethnicity unlikely affect the diagnostic accuracy for RCC. By contrast, the relative expression of lncRNAs significantly influenced sensitivity. Hence, the down-regulation of lncRNA expression may exhibits a higher sensitivity in the diagnosis of RCC.

\section{DISCUSSION}

Over the past decade, there were a lot of researches studying on lncRNAs. Increasing evidence showed that aberrant expression of IncRNAs was associated with clinical outcomes for cancer patients. LncRNAs were also closely related to cancer, they were considered eminent players in cancer biology. The up-regulation or down-regulation of many lncRNAs contributed to oncogenesis by affecting many cellular processes [36].
In order to find some biomarkers for RCC, we conducted this comprehensive systematic review and meta-analysis of the current literature. The present meta-analysis is the first to systematically analyze the association between lncRNA expression and clinical features of RCC, a total of 14 studies were included.

In the classification of clinicopathological features, dysregulated RCCRT1 [23], SPRY4-IT1 [24], H19 [21], NONHSAT123350 [29], and ATB [22] could potentially be exploited as novel biomarkers to detect distant metastasis in patients with RCC in early stages. Furthermore, RCCRT1 [23], SPRY4-IT1 [24], NBAT1 [27], MALAT1 [25], and ATB [22] might be used as biomarkers of lymph node metastasis. Although these IncRNAs were associated with the clinicopathological features of patients with RCC; most of these lncRNAs were detected by single study; among these lncRNAs,

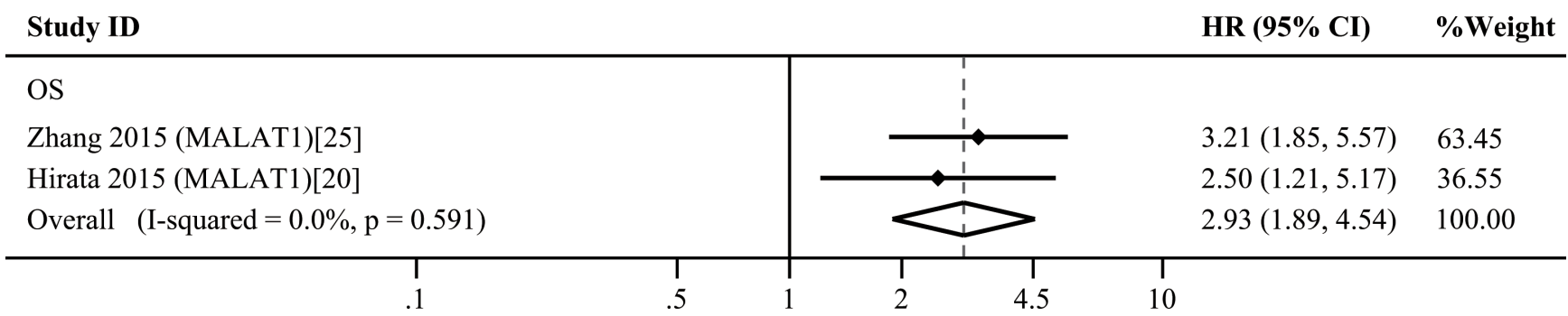

Figure 4: Forest plots of studies evaluating hazard ratios of up-regulated MALAT1 expression and the overall survival (OS) of RCC patients. 
(a) Forest plot of sensitivity

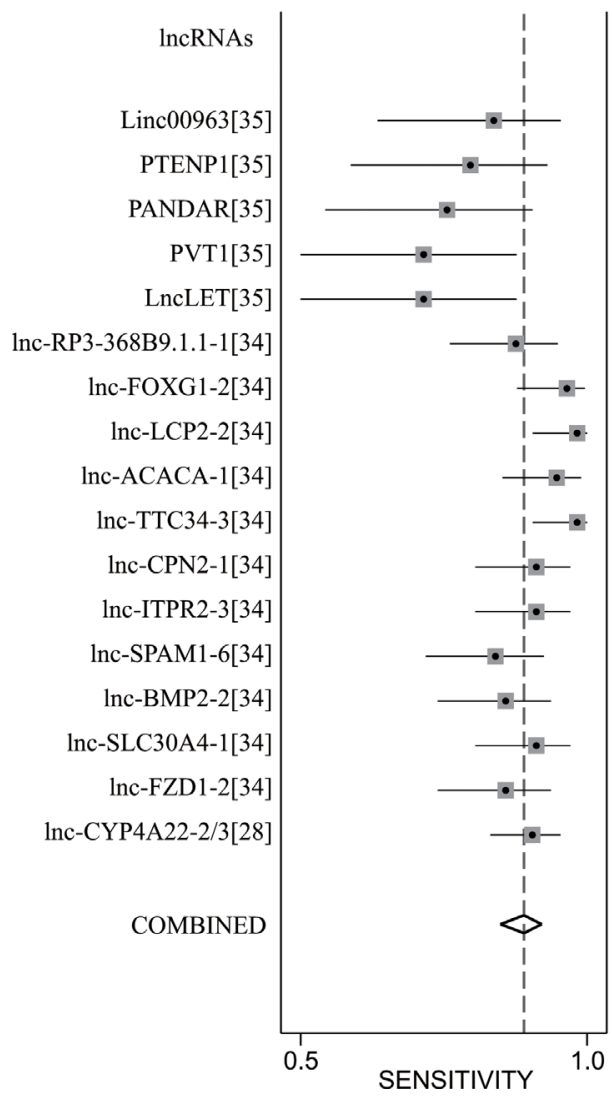

(b) Forest plot of specificity

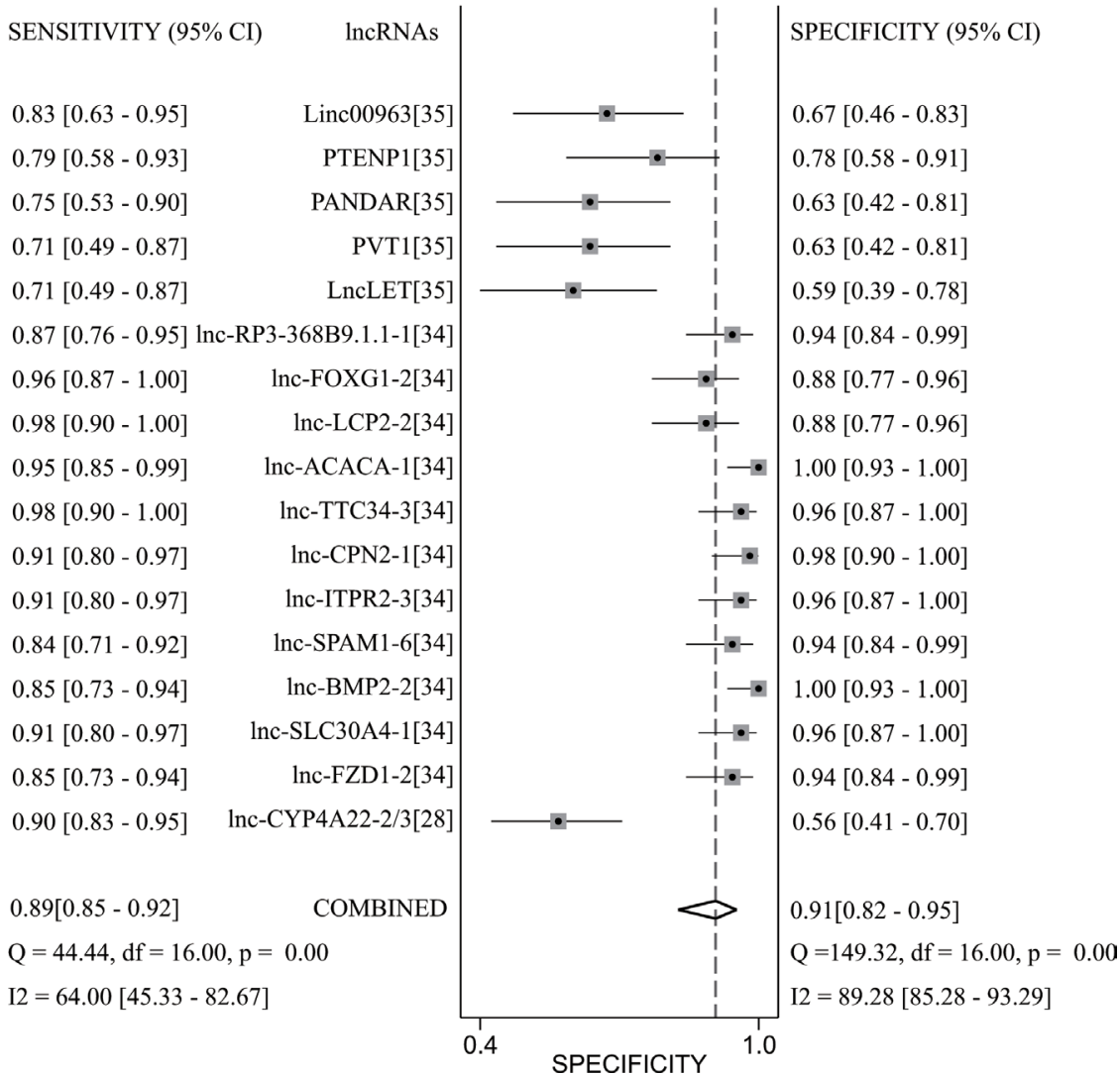

Figure 5: Forest plot of sensitivity a. and specificity b. of IncRNAs for the diagnosis of RCC.

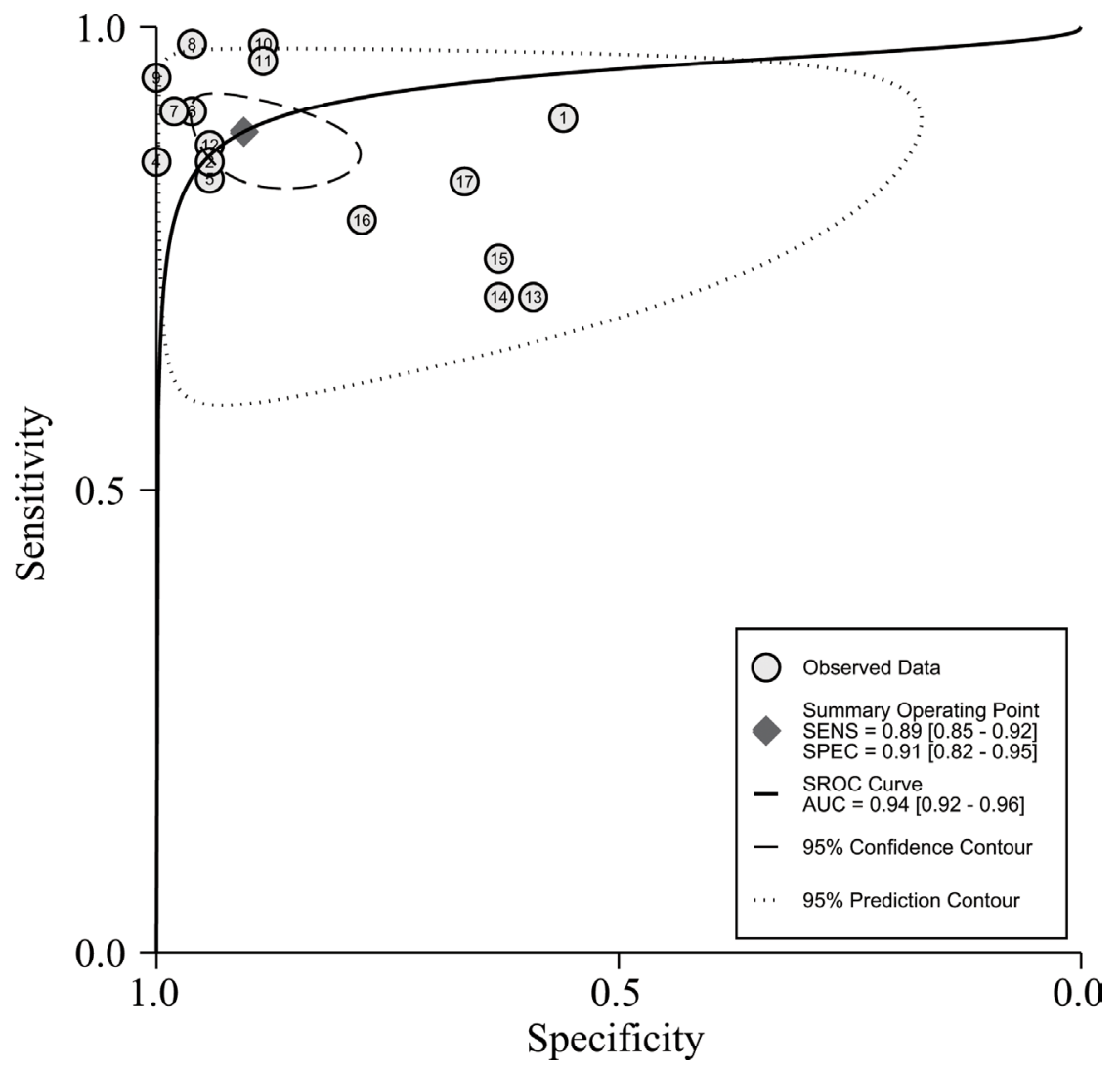

Figure 6: The summary receiver operator characteristic (SROC) curve based on all IncRNAs. 
MALAT1 was the most investigated and reported by two studies; this lncRNA was significantly associated with the tumor stage and lymph node metastasis of patients with RCC after we pooled OR and $p$-value. However, this conclusion may be insufficiently persuasive because these two studies used different cutoff values to distinguish high and low expression levels. Further studies should be performed because of the limitations of the included studies to verify these conclusions.

Regarding the prognostic value, the increased expression of four lncRNAs was associated with poor prognosis, as was the decreased expression of six lncRNAs. Although these lncRNAs were associated with the prognosis of patients with RCC, only MALAT1 was reported by two studies. We then conducted a metaanalysis on the relationship of MALAT1 expression and the OS of patients with RCC. The results revealed that a high MALAT1 expression predicted poor survival among patients with RCC; as such, these patients likely exhibited a short OS. However, this conclusion may be insufficiently persuasive because of the small size of this study. Thus, further research should be conducted to verify this conclusion.

For diagnostic value, the pooled result showed that lncRNA maintained high sensitivity and specificity in RCC diagnosis. PLR and NLR were applied to judge the clinical applicability of IncRNA for diagnosis, and the PLR $>10$ and NLR $<0.1$ represent a high diagnostic accuracy [32].

\section{(a) Meta-regression of sensitivity}

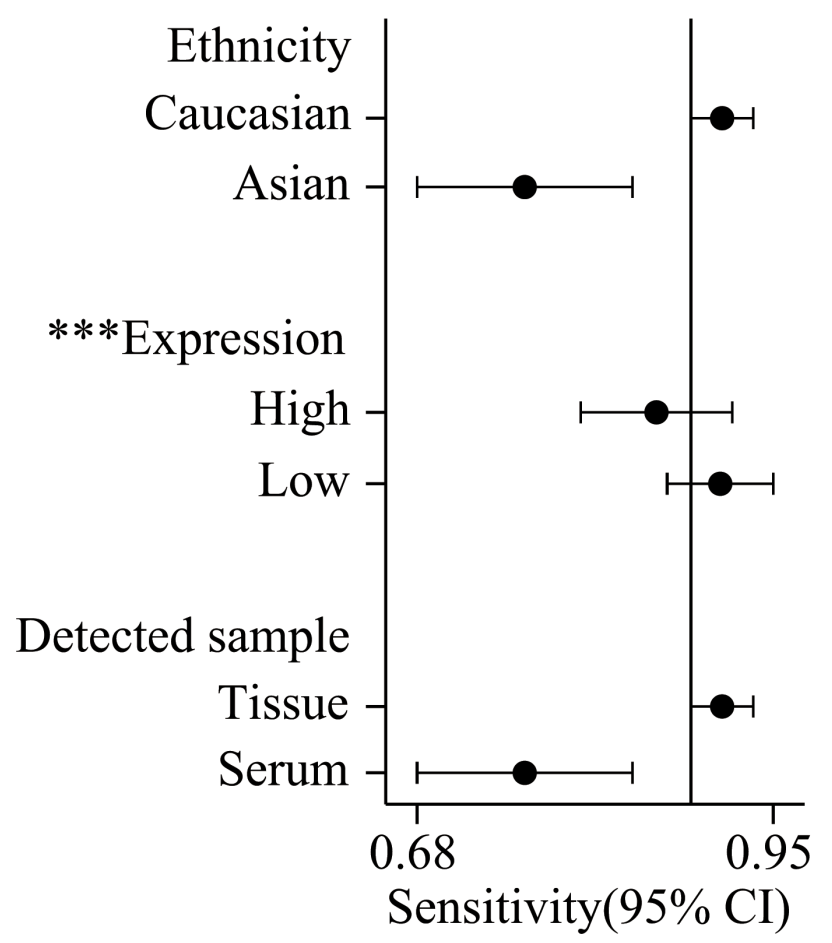

The pooled PLR and NLR obtained in our study showed a satisfactory diagnostic accuracy. The AUC of 0.94 for lncRNA in RCC diagnosis also indicated a significant advantage over other biomarkers. Considering that significant heterogeneity was observed in sensitivity and specificity data, we then performed a subgroup analysis on ethnicity, lncRNA expression level and detected sample types which may influence the heterogeneity. We found that detection and ethnicity unlikely affected the diagnostic accuracy for RCC. By contrast, the lncRNA expression level significantly affected sensitivity. Therefore, the down-regulated lncRNAs may exhibit a higher sensitivity for the diagnosis of RCC. However, we were unable to perform advanced analysis because of the limited number of studies and insufficient number of articles regarding other lncRNAs. Nevertheless, these limited data still fuel our imagination. As we can see, the diagnostic value of single lncRNA was high enough, if we merge some of them, can we improve the diagnostic rate of RCC? Wu et al. [35] reported that the AUC of a 5-lncRNA signature, including lncRNA-LET, PVT1, PANDAR, PTENP1 and linc00963 was higher than that of one lncRNA after they detected serum samples from 71 ccRCC patients, 62 healthy controls, and 8 patients with benign renal tumors. Moreover, five-minus-one lncRNA signatures yield that none of the lncRNAs had a higher AUC than the other lncRNAs do [35]. Jicheng Tantai et al. [15] reported that combination of lncRNA-XIST and lncRNA HIF1A-AS1

\section{(b) Meta-regression of specificity}

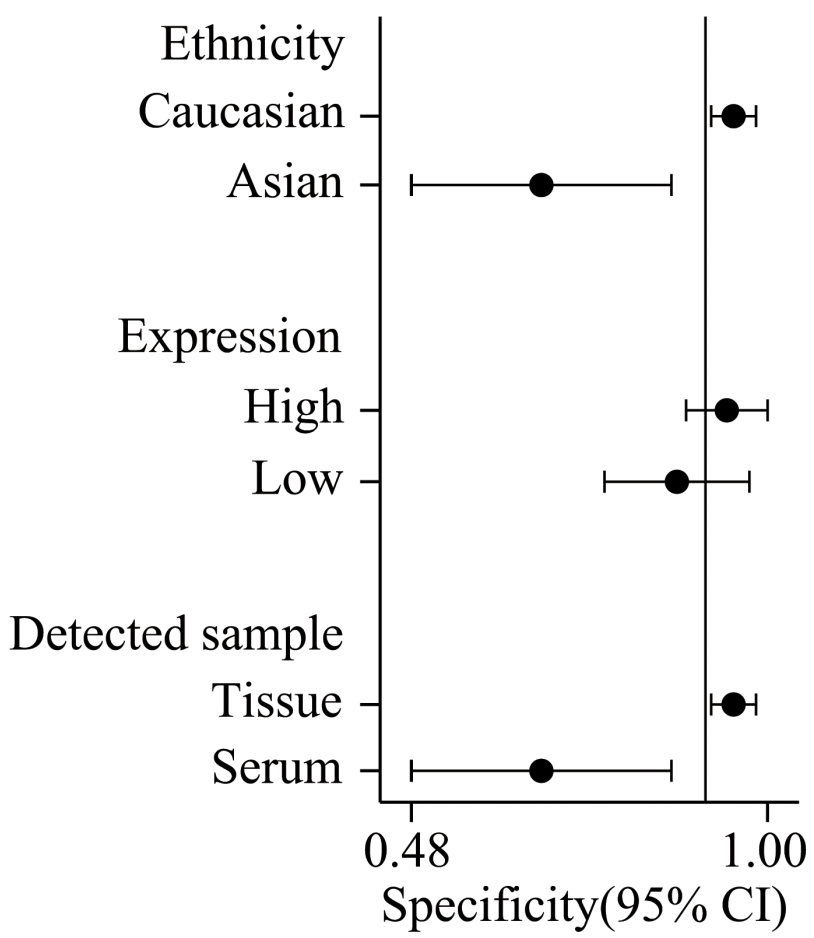

Figure 7: Univariate meta-regression and subgroup analysis for sensitivity a. and specificity b. of IncRNAs for the diagnosis of $\mathbf{R C C}(* p<0.05, * * p<0.01, * * * p<0.001)$. 
had a higher positive diagnostic efficiency of NSCLC than XIST or HIF1A-AS1 alone. From this point of view, it provided a promising way to determine biomarkers for the diagnosis of RCC. However, further large-scale studies should be conducted to verify this method.

Our study revealed that MALAT1 was correlated not only with clinicopathological features but also with RCC prognosis; MALAT1 was the most investigated lncRNA in RCC. Thus, the application of MALAT1 is possibly the most promising lncRNA for future studies. MALAT1 is a widely expressed and highly conserved nuclear-abundant lncRNA with a length of approximately 8000 nucleotides [37]. MALAT1 was first identified as an independent prognostic biomarker that can predict metastasis and survival in early stage non-small cell lung cancer (NSCLC) [38]. MALAT1 was highly expressed in several cancer types, such as NSCLC [38], gastric cancer [39], colorectal cancer [40], breast cancer [41], cervical cancer [42], prostate cancer [43], nasopharyngeal cancer [44], and renal cancer [25]. The up-regulation of the MALAT1 expression was associated with the clinical parameters and poor prognostic outcome of cancer patients, this finding is consistent with our results. Many molecular mechanisms could explain this relationship. Hirata et al. [20] reported that MALAT1 silencing decreased RCC cell proliferation and invasion but increases apoptosis. This phenomenon promoted aggressive RCC through Ezh2 and interacts with miR-205; this phenomenon also regulated EMT and $\beta$-catenin signaling pathways in renal cancer cells. Furthermore, miR-125b binded to MALAT1 and decreased the expression level of MALAT1.

Despite the scope of this systematic and comprehensive meta-analysis, several limitations should be considered. First, the number of studies included in our meta-analysis was insufficient and the sample size was limited. Most of these studies contained diverse lncRNAs and used different follow-up endpoints, and one lncRNA was identified by two studies. Hence, a premature result may be obtained. Further studies should be conducted when more eligible studies are published. Furthermore, we did not evaluate publication bias in our study because of inadequate data. As literature-based analyses, studies with positive results were more likely to be published. However, the lack of these analyses can amplify the association between lncRNAs and clinical values of RCC, which may partly affect the interpretation and reliability of results. Second, the cutoff value and method for low or high levels of lncRNA varied in different studies, although qRT-PCR was the standard method used to evaluate the expression of IncRNA, which may cause the heterogeneity of results. Therefore, researchers should develop a cutoff value with enhanced consistency and establish a method to classify high or low lncRNA expression. Finally, a remarkable heterogeneity was observed in the analysis of diagnostic value. The heterogeneity of the subjects was composed of different factors, such as patients' baseline characteristics and different cut-off methods. Although we performed the subgroup analysis and found that lncRNA expression level was one of the sources of heterogeneity, this bias could not be accounted for the entire source.

In summary, our study is the first meta-analysis to evaluate the expression of lncRNAs and clinical values of patients with RCC. Despite these limitations, our analysis revealed that lncRNAs could be considered biomarkers for lymph node metastasis and distant metastasis in early stages. Furthermore, lncRNAs could be potential prognostic markers for RCC. LncRNAs also exhibited high diagnostic accuracy for RCC diagnosis. What's more, MALAT1 was associated with tumor stage and could be considered a biomarker for lymph node metastasis in early stages, and high MALAT1 expression predicted poor survival among patients with RCC. However, further comprehensive, large-scale, and good quality studies should be conducted to confirm our findings and to verify the clinical values of lncRNAs in RCC.

\section{MATERIALS AND METHODS}

\section{Search strategy}

We performed a literature search on up-to-date electronic databases, including Pubmed, Embase, and Web of Science for studies that analyzed the relationship between lncRNAs and clinical values (clinicopathology, prognosis, and diagnosis) in RCC patients on May 25th, 2016. We mainly searched three key aspects "IncRNA" , "cancer", and "renal", following was the detail search strategy in Pubmed: (lncRNA OR lncRNAs OR lincRNA $O R$ lincRNAs $O R$ "long non-coding $R N A$ " $O R$ "long noncoding $R N A$ " $O R$ "long intergenic noncoding $R N A$ " OR "long non protein coding RNA" OR H19) AND (cancer OR carcinoma OR neoplasm OR tumor OR tumors $O R$ tumour $O R$ tumours $O R$ malignancy $O R$ metastasis) AND (renal OR renals OR kidney OR kidneys OR RCC OR "renal cell carcinoma" OR (renal AND cell $A N D$ carcinoma) OR "renal cell cancer" OR (renal AND cell AND cancer) ). The literature covered was limited to human and English. Additionally, we screened the references from many relevant literatures, including all of the identified studies, reviews, and editorials.

\section{Eligibility criteria and quality assessment}

The inclusion criteria were as follows: (1) studies that investigated the association between the expression of IncRNAs and clinicopathological features, and the expression level of lncRNAs had to be divided into two levels: high or low; or (2) studies that detected lncRNA concentrations in serum or tissue and presented sufficient data, including sensitivity, specificity, and sample size, to 
allow us to perform statistical analysis and construction of two-by-two tables; or (3) studies that investigated the association between lncRNA expression and survival outcome and provided a HR or relative risk (RR), 95\% $\mathrm{CI}$ or $p$ value, and Kaplan-Meier curves or required data obtained by contacting corresponding authors.

The exclusion criteria were as follows: (1) nonEnglish paper; (2) non-human data; (3) studied only in cellular level; (4) letters, case reports, commentaries, conference abstracts or review articles; (5) sample cases fewer than 30; (6) studies focusing on lncRNA genetic alterations, including methylation patterns or polymorphisms; (7) HRs calculated on the basis of multiple lncRNAs; and (8) insufficient data for HR and $95 \% \mathrm{CI}$ estimation. We included the most recent and informative article when overlapping studies were retrieved.

Two investigators (Jianwen Chen and Yalei Chen) independently assessed the quality of all the included diagnostic studies according to the Quality Assessment of Diagnostic Accuracy Studies-2 (QUADAS-2) criteria [33]. The QUADAS-2 tool comprises four key domains: patient selection, index test, reference standard, flow and timing, and judge bias and applicability. Each domain is assessed in terms of risk of bias, and the first 3 domains are also assessed in terms of concerns regarding applicability. Each item is answered with "yes," "no," or "unclear". The answer of "yes" means low risk of bias, while "no" or "unclear" means the opposite.

\section{Data extraction}

Data were retrieved independently by two investigators (Jianwen Chen and Yalei Chen), and the information of all the included studies were extracted using a predefined sheet which based on the reporting checklists of Preferred Reporting Items for Systematic Reviews and Meta-analysis (PRISMA) [45]. Data retrieved from the articles included the following items: (1) publication information: first author's last name, publication year and study design; (2) patients' characteristic information: study population and regions, sample size, and follow-up duration; (3) RCC cancer information: tumor type, and clinical tumor stage; (4) lncRNA information: detection methods, cut-off definition, and relationship between lncRNAs and survival outcome or clinicopathological features; and (5) sensitivity, specificity, AUC, and sample sizes for diagnostic analysis and two-by-two table construction; (6) HRs, $95 \% \mathrm{CI}$ and $p$-value for survival analysis, if available, these data were obtained from the original article; otherwise, corresponding authors were contacted to collect these data; if Kaplan-Meier curves were available, data were extracted from graphical survival plots and HRs were estimated [46].

\section{Statistical analysis}

A test of heterogeneity among studies was conducted using I-squared statistic, $\mathrm{I}^{2}$ values of $>50 \%$ indicated that there was a substantial between-study heterogeneity existed. The potential sources of heterogeneity were further identified by subgroup analysis. A fixed effect model was applied for the meta-analysis with moderate heterogeneity $\left(\mathrm{I}^{2}<50 \%\right)$; otherwise, a random effect model was used $[47,48]$. A different effect size (ES) was selected for each meta-analysis. (1) OR and a 95\% CI were used for the meta-analysis of clinicopathological features. (2) For the prognostic meta-analysis, the $\ln \mathrm{HR}$ and standard error were used for aggregation of the survival results. An observed HR $>1$ implied a worse survival for the group with elevated lncRNA expression. Conversely, an observed $\mathrm{HR}<1$ implied a worse survival for the group with decreased lncRNA expression [47]. (3) Sensitivity, specificity, PLR, NLR, DOR, SROC curve, and AUC were used for the diagnostic meta-analysis. All analyses were performed using the Stata Statistical software version 12.0 (StataCorp, College Station, TX, USA), and $p<0.05$ was considered to be significant.

\section{ACKNOWLEDGMENTS AND FUNDING}

This work was financially supported by the People's Republic of China and the National High Technology Research and Development Program ("863"Program) of China: the screening and clinical validation of characteristic protein biomarkers in renal cancer based on a large-scale biobank (2014AA020607), and also sponsored by the National Natural Science Foundation of China: the research on the mechanism of long non-coding RNA regulating the calcium binding protein S100A6 in clear cell renal cell carcinoma(81502448).

\section{CONFLICTS OF INTEREST}

The authors declare no conflict of interest.

\section{REFERENCES}

1. Chen W, Zheng R, Baade PD, Zhang S, Zeng H, Bray F, Jemal A, Yu XQ and He J. Cancer statistics in China, 2015. CA Cancer J Clin. 2016; 66:115-32.

2. Murai M and Oya M. Renal cell carcinoma: etiology, incidence and epidemiology. Current opinion in urology. 2004; 14(4):229-233.

3. Jemal A, Siegel R, Ward E, Hao Y, Xu J, Murray T and Thun MJ. Cancer statistics, 2008. CA Cancer J Clin. 2008; 58(2):71-96.

4. Wan L, Huang J, Chen J, Wang R, Dong C, Lu S and Wu X. Expression and significance of FOXP1, HIF-1a and VEGF in renal clear cell carcinoma. Journal of BUON. 2015; 
20(1):188-195.

5. Liu S, Ma X, Ai Q, Huang Q, Shi T, Zhu M, Wang B and Zhang X. NOTCH1 functions as an oncogene by regulating the PTEN/PI3K/AKT pathway in clear cell renal cell carcinoma. Urologic oncology. 2013; 31(6):938-948.

6. Lyu XJ, Li HZ, Ma X, Li XT, Gao Y, Ni D, Shen DL, $\mathrm{Gu}$ LY, Wang BJ, Zhang Y and Zhang X. Elevated S100A6 (Calcyclin) enhances tumorigenesis and suppresses CXCL14-induced apoptosis in clear cell renal cell carcinoma. Oncotarget. 2015; 6(9):6656-6669. doi: 10.18632/oncotarget.3169.

7. Ma X, Gao Y, Fan Y, Ni D, Zhang Y, Chen W, Zhang P, Song E, Huang Q, Ai Q, Li H, Wang B, Zheng T, Shi T and Zhang $\mathrm{X}$. Overexpression of E2F1 promotes tumor malignancy and correlates with TNM stages in clear cell renal cell carcinoma. PloS one. 2013; 8(9):e73436.

8. Cao J, Liu J, Xu R, Zhu X, Liu L and Zhao X. MicroRNA-21 stimulates epithelial-to-mesenchymal transition and tumorigenesis in clear cell renal cells. Molecular medicine reports. 2016; 13(1):75-82.

9. Fu B, Wang Y, Zhang X, Lang B, Zhou X, Xu X, Zeng T, Liu W, Zhang X, Guo J and Wang G. MiR-221-induced PUMA silencing mediates immune evasion of bladder cancer cells. International journal of oncology. 2015; 46(3):1169-1180.

10. Huang QB, Ma X, Zhang X, Liu SW, Ai Q, Shi TP, Zhang Y, Gao Y, Fan Y, Ni D, Wang BJ, Li HZ and Zheng T. Down-Regulated miR-30a in Clear Cell Renal Cell Carcinoma Correlated with Tumor Hematogenous Metastasis by Targeting Angiogenesis-Specific DLL4. PloS one. 2013; 8(6):e67294.

11. Guttman M and Rinn JL. Modular regulatory principles of large non-coding RNAs. Nature. 2012; 482(7385):339-346.

12. Sanchez $Y$ and Huarte M. Long non-coding RNAs: challenges for diagnosis and therapies. Nucleic acid therapeutics. 2013; 23(1):15-20.

13. Huarte M, Guttman M, Feldser D, Garber M, Koziol MJ, Kenzelmann-Broz D, Khalil AM, Zuk O, Amit I, Rabani M, Attardi LD, Regev A, Lander ES, Jacks T and Rinn JL. A large intergenic noncoding RNA induced by p53 mediates global gene repression in the p53 response. Cell. 2010; 142(3):409-419.

14. Dijkstra JM and Alexander DB. The "NF-k B interacting long noncoding RNA" ( NKILA) transcript is antisense to cancer-associated gene PMEPA1. F1000Research. 2015; 4:96.

15. Tantai J, Hu D, Yang Y and Geng J. Combined identification of long non-coding RNA XIST and HIF1A-AS1 in serum as an effective screening for non-small cell lung cancer. International journal of clinical and experimental pathology. 2015; 8(7):7887-7895.

16. Gao J, Cao R and Mu H. Long non-coding RNA UCA1 may be a novel diagnostic and predictive biomarker in plasma for early gastric cancer. International journal of clinical and experimental pathology. 2015; 8(10):12936-12942.

17. Wang XS, Zhang Z, Wang HC, Cai JL, Xu QW, Li MQ, Chen YC, Qian XP, Lu TJ, Yu LZ, Zhang Y, Xin DQ, Na YQ and Chen WF. Rapid identification of UCA1 as a very sensitive and specific unique marker for human bladder carcinoma. Clin Cancer Res. 2006; 12(16):4851-4858.

18. Yuan JH, Yang F, Wang F, Ma JZ, Guo YJ, Tao QF, Liu F, Pan W, Wang TT, Zhou CC, Wang SB, Wang YZ, Yang Y, Yang N, Zhou WP, Yang GS, et al. A long noncoding RNA activated by TGF-beta promotes the invasion-metastasis cascade in hepatocellular carcinoma. Cancer cell. 2014; 25(5):666-681.

19. Liu XH, Liu ZL, Sun M, Liu J, Wang ZX and De W. The long non-coding RNA HOTAIR indicates a poor prognosis and promotes metastasis in non-small cell lung cancer. BMC cancer. 2013; 13:464.

20. Hirata H, Hinoda Y, Shahryari V, Deng G, Nakajima K, Tabatabai ZL, Ishii N and Dahiya R. Long Noncoding RNA MALAT1 Promotes Aggressive Renal Cell Carcinoma through Ezh2 and Interacts with miR-205. Cancer research. 2015; 75(7):1322-1331.

21. Wang L, Cai Y, Zhao X, Jia X, Zhang J, Liu J, Zhen H, Wang T, Tang X, Liu Y and Wang J. Down-regulated long non-coding RNA H19 inhibits carcinogenesis of renal cell carcinoma. Neoplasma. 2015; 62(3):412-418.

22. Xiong J, Liu $\mathrm{Y}$, Jiang $\mathrm{L}$, Zeng $\mathrm{Y}$ and Tang W. High expression of long non-coding RNA lncRNA-ATB is correlated with metastases and promotes cell migration and invasion in renal cell carcinoma. Japanese journal of clinical oncology. 2016; 46(4):378-84.

23. Song S, Wu Z, Wang C, Liu B, Ye X, Chen J, Yang Q, Ye $\mathrm{H}, \mathrm{Xu} \mathrm{B}$ and Wang L. RCCRT1 is correlated with prognosis and promotes cell migration and invasion in renal cell carcinoma. Urology. 2014; 84(3):730.e731-737.

24. Zhang HM, Yang FQ, Yan Y, Che JP and Zheng JH. High expression of long non-coding RNA SPRY4-IT1 predicts poor prognosis of clear cell renal cell carcinoma. International journal of clinical and experimental pathology. 2014; 7(9):5801-5809.

25. Zhang HM, Yang FQ, Chen SJ, Che J and Zheng JH. Upregulation of long non-coding RNA MALAT1 correlates with tumor progression and poor prognosis in clear cell renal cell carcinoma. Tumor Biol. 2015; 36(4):2947-2955.

26. Yao J, Chen Y, Wang Y, Liu S, Yuan X, Pan F and Geng P. Decreased expression of a novel lncRNA CADM1-AS1 is associated with poor prognosis in patients with clear cell renal cell carcinomas. International journal of clinical and experimental pathology. 2014; 7(6):2758-2767.

27. Xue S, Li QW, Che JP, Guo Y, Yang FQ and Zheng JH. Decreased expression of long non-coding RNA NBAT-1 is associated with poor prognosis in patients with clear cell renal cell carcinoma. International journal of clinical and experimental pathology. 2015; 8(4):3765-3774.

28. Ellinger J, Alam J, Rothenburg J, Deng M, Schmidt D, 
Syring I, Miersch H, Perner S and Muller SC. The long non-coding RNA lnc-ZNF180-2 is a prognostic biomarker in patients with clear cell renal cell carcinoma. American journal of cancer research. 2015; 5(9):2799-2807.

29. Liu H, Chen P, Jiang C, Han J, Zhao B, Ma Y and Mardan M. Screening for the key lncRNA targets associated with metastasis of renal clear cell carcinoma. Medicine (United States). 2016; 95(2).

30. Sakurai K, Reon BJ, Anaya J and Dutta A. The lncRNA DRAIC/PCAT29 Locus Constitutes a Tumor-Suppressive Nexus. Molecular cancer research. 2015; 13(5):828-838.

31. Xu S, Wang P, You Z, Meng H, Mu G, Bai X, Zhang G, Zhang $J$ and Pang D. The long non-coding RNA EPB41L4A-AS2 inhibits tumor proliferation and is associated with favorable prognoses in breast cancer and other solid tumors. Oncotarget. 2016; 7:20704-17. doi: 10.18632/oncotarget.8007.

32. Hayes DF, Isaacs C and Stearns V. Prognostic factors in breast cancer: current and new predictors of metastasis. Journal of mammary gland biology and neoplasia. 2001; 6(4):375-392.

33. Whiting PF, Rutjes AW, Westwood ME, Mallett S, Deeks JJ, Reitsma JB, Leeflang MM, Sterne JA and Bossuyt PM. QUADAS-2: a revised tool for the quality assessment of diagnostic accuracy studies. Annals of internal medicine. 2011; 155(8):529-536.

34. Blondeau JJ, Deng M, Syring I, Schrodter S, Schmidt D, Perner S, Muller SC and Ellinger J. Identification of novel long non-coding RNAs in clear cell renal cell carcinoma. Clinical epigenetics. 2015; 7(1):10.

35. Wu Y, Wang YQ, Weng WW, Zhang QY, Yang XQ, Gan HL, Yang YS, Zhang PP, Sun MH, Xu MD and Wang CF. A serum-circulating long noncoding RNA signature can discriminate between patients with clear cell renal cell carcinoma and healthy controls. Oncogenesis. 2016; 5:e192.

36. Ma L, Bajic VB and Zhang Z. On the classification of long non-coding RNAs. RNA biology. 2013; 10(6):925-933.

37. Tripathi V, Ellis JD, Shen Z, Song DY, Pan Q, Watt AT, Freier SM, Bennett CF, Sharma A, Bubulya PA, Blencowe BJ, Prasanth SG and Prasanth KV. The nuclear-retained noncoding RNA MALAT1 regulates alternative splicing by modulating SR splicing factor phosphorylation. Molecular cell. 2010; 39(6):925-938.

38. Ji P, Diederichs S, Wang W, Boing S, Metzger R, Schneider PM, Tidow N, Brandt B, Buerger H, Bulk E, Thomas M, Berdel WE, Serve H and Muller-Tidow C. MALAT-1, a novel noncoding RNA, and thymosin beta4 predict metastasis and survival in early-stage non-small cell lung cancer. Oncogene. 2003; 22(39):8031-8041.
39. Qi Y, Ooi HS, Wu J, Chen J, Zhang X, Tan S, Yu Q, Li YY, Kang Y, Li H, Xiong Z, Zhu T, Liu B, Shao Z and Zhao X. MALAT1 long ncRNA promotes gastric cancer metastasis by suppressing PCDH10. Oncotarget. 2016; 7:12693-703. doi: 10.18632/oncotarget.7281.

40. Hu ZY, Wang XY, Guo WB, Xie LY, Huang YQ, Liu YP, Xiao LW, Li SN, Zhu HF, Li ZG and Kan H. Long noncoding RNA MALAT1 increases AKAP-9 expression by promoting SRPK1-catalyzed SRSF1 phosphorylation in colorectal cancer cells. Oncotarget. 2016; 7:11733-43. doi: 10.18632/oncotarget.7367.

41. Jin C, Yan B, Lu Q, Lin Y and Ma L. Reciprocal regulation of Hsa-miR-1 and long noncoding RNA MALAT1 promotes triple-negative breast cancer development. Tumor Biol. 2016; 37:7383-94.

42. Zhang Y, Wang T, Huang HQ, Li W, Cheng XL and Yang J. Human MALAT-1 long non-coding RNA is overexpressed in cervical cancer metastasis and promotes cell proliferation, invasion and migration. Journal of BUON. 2015; 20(6):1497-1503.

43. Wang D, Ding L, Wang L, Zhao Y, Sun Z, Karnes RJ, Zhang $J$ and Huang H. LncRNA MALAT1 enhances oncogenic activities of EZH2 in castration-resistant prostate cancer. Oncotarget. 2015; 6(38):41045-41055. doi: 10.18632/oncotarget.5728.

44. Jin C, Yan B, Lu Q, Lin Y and Ma L. The role of MALAT1/ $\mathrm{miR}-1 /$ slug axis on radioresistance in nasopharyngeal carcinoma. Tumor Biol. 2015.

45. Liberati A, Altman DG, Tetzlaff J, Mulrow C, Gotzsche PC, Ioannidis JP, Clarke M, Devereaux PJ, Kleijnen J and Moher D. The PRISMA statement for reporting systematic reviews and meta-analyses of studies that evaluate healthcare interventions: explanation and elaboration. BMJ (Clinical research ed). 2009; 339:b2700.

46. Tierney JF, Stewart LA, Ghersi D, Burdett S and Sydes MR. Practical methods for incorporating summary time-toevent data into meta-analysis. Trials. 2007; 8:16.

47. Ding X, Wan X, Jiang H, Song H, Fang Y, Chen S, Li P and Guo J. The clinical value of ncRNAs in gastric cancer: a systematic review and meta-analyses. Tumor Biol. 2015; 36(6):4017-4025.

48. Gu L, Li H, Chen L, Ma X, Gao Y, Li X, Zhang Y, Fan $\mathrm{Y}$ and Zhang $\mathrm{X}$. MicroRNAs as prognostic molecular signatures in renal cell carcinoma: a systematic review and meta-analysis. Oncotarget. 2015; 6(32):32545-32560. doi: 10.18632/oncotarget.5324. 